\title{
Does Motivation Matter? Analysis of a Randomized Trial of Proactive Outreach to VA Smokers
}

\author{
Elisheva R. Danan, MD, MPH ${ }^{1,2}$, Anne M. Joseph, MD, MPH', Scott E. Sherman, MD, MPH ${ }^{3,4}$, \\ Diana J. Burgess, $P h D^{1,2}$, Siamak Noorbaloochi, $P h D^{1,2}$, Barbara Clothier, $M S^{1}$, \\ Sandra J. Japuntich, PhD ${ }^{5,6}$, Brent C. Taylor, PhD ${ }^{1,2}$, and Steven S. Fu, MD, MSCE ${ }^{1,2}$ \\ 'VA HSR\&D Center for Chronic Disease Outcomes Research, Minneapolis VA Health Care System, Minneapolis, MN, USA; ${ }^{2}$ Department of \\ Medicine, University of Minnesota Medical School, Minneapolis, MN, USA; ${ }^{3}$ VA New York Harbor Healthcare System, New York City, NY, USA; \\ ${ }^{4}$ Department of Population Health, New York University School of Medicine, New York City, NY, USA; ${ }^{5}$ National Center for PTSD, VA Boston \\ Healthcare System, Boston, MA, USA; ${ }^{6}$ Department of Psychiatry, Boston University School of Medicine, Boston, MA, USA.
}

BACKGROUND: Current guidelines advise providers to assess smokers' readiness to quit, then offer cessation therapies to smokers planning to quit and motivational interventions to smokers not planning to quit.

OBJECTIVES: We examined the relationship between baseline stage of change (SOC), treatment utilization, and smoking cessation to determine whether the effect of a proactive smoking cessation intervention was dependent on smokers' level of motivation to quit.

DESIGN: Secondary analysis of a multicenter randomized controlled trial.

PARTICIPANTS: A total of 3006 current smokers, aged 18-80 years, at four Veterans Affairs (VA) medical centers. Interventions: Proactive care included proactive outreach (mailed invitation followed by telephone outreach), offer of smoking cessation services (telephone or face-to-face), and access to pharmacotherapy. Usual care participants had access to VA smoking cessation services and state telephone quitlines.

MAIN MEASURES: Baseline SOC measured with Readiness to Quit Ladder, and 6-month prolonged abstinence self-reported at 1 year.

KEY RESULTS: At baseline, $35.8 \%$ of smokers were in preparation, $38.2 \%$ in contemplation, and $26.0 \%$ in precontemplation. The overall interaction between SOC and treatment arm was not statistically significant $(\mathrm{p}=0.30)$. Among smokers in preparation, $21.1 \%$ of proactive care participants achieved 6-month prolonged abstinence, compared to $13.1 \%$ of usual care participants (OR, 1.8 [95 \% CI, 1.2-2.6]). Similarly, proactive care increased abstinence among smokers in contemplation (11.0 \% vs. $6.5 \%$; OR, 1.8 [95 \% CI, 1.1-2.8]). Smokers in precontemplation quit smoking at similar rates $(5.3 \%$ vs. $5.6 \%$; OR, 0.9 [95 \% CI, 0.5-1.9]). Within each stage, uptake of smoking cessation treatments increased with higher SOC and with proactive care as compared with usual care.

LIMITATIONS: Mostly male participants limits generalizability. Randomization was not stratified by SOC.

Registration: ClinicalTrials.gov Identifier NCT00608426

Received November 2, 2015

Revised February 10, 2016

Accepted March 17, 2016

Published online April 12, 2016
CONCLUSIONS: Proactive care increased treatment uptake compared to usual care across all SOC. Proactive care increased smoking cessation among smokers in preparation and contemplation but not in precontemplation. Proactively offering cessation therapies to smokers at all SOC will increase treatment utilization and population-level smoking cessation.

KEY WORDS: smoking cessation; motivation; veterans. J Gen Intern Med 31(8):878-87

DOI: $10.1007 / \mathrm{s} 11606-016-3687-1$

(C) The Author(s) 2016. This article is published with open access at Springerlink.com

\section{INTRODUCTION}

Current US smokers overwhelmingly want to quit $(68.8 \%)$, and most make at least one quit attempt each year (52.4\%), yet they rarely achieve sustained abstinence (6.2\% per year). ${ }^{1}$ As a result, the prevalence of smoking in the US has plateaued at approximately $18 \%$ of adults. ${ }^{2}$ Evidence-based smoking cessation therapies such as medication and counseling significantly increase the success of quit attempts, ${ }^{3,4}$ but these therapies are underutilized. ${ }^{1,5}$ Current models of care for tobacco cessation treatment rely on highly motivated smokers to initiate therapy (e.g., by calling state telephone quitlines) or on clinical providers to offer therapy. The US Clinical Practice Guideline ${ }^{6}$ instructs providers to offer active therapy only to smokers who are "willing" to quit in the next 30 days. The guideline recommends that smokers who are not ready to quit receive brief motivational interventions (e.g., motivational interviewing) to enhance readiness to quit.

The theoretical justification for evaluating smokers' readiness to quit prior to offering therapy is rooted in the transtheoretical model (TTM). ${ }^{7}$ This model describes progression through five stages of change (SOC) (precontemplation, contemplation, and preparation for current smokers; action and maintenance for those who have quit) that correlate with ten processes of behavior change. Hundreds of published validation, population, and intervention studies have evaluated the TTM in 
the context of tobacco use. ${ }^{8,9}$ According to the TTM, "action-oriented" interventions such as cessation pharmacotherapy are most effective in the advanced stages. ${ }^{10-12}$ Unfortunately, $80 \%$ of U.S. smokers have historically fallen into the precontemplation and contemplation stages. $^{13,14}$ As motivated smokers have quit in response to public health campaigns and policy initiatives, ${ }^{15}$ the proportion of smokers in preparation has dropped even further, with levels now at only $9-12 \% .{ }^{16,17}$ Efforts to help early-stage smokers transition to higher stages through motivational interviewing have produced mixed results. ${ }^{18}$ As the percentage of smokers in preparation shrinks, the practice of offering active therapy only to those preparing to quit will have diminishing returns.

While the TTM has served as a useful framework for understanding behavior change, it has limitations as the basis for clinical practice guidelines. The TTM systematically underestimates smokers' motivation to quit, ${ }^{19-21}$ as many, if not most, precontemplators and contemplators both want to and try to quit. ${ }^{22}$ In fact, several interventions have documented successful abstinence among precontemplators and contemplators. ${ }^{23-25}$ These results substantiate critiques of the construct validity $^{21,26-28}$ and inherent instability of the TTM stages. ${ }^{21,29}$ Interventions that proactively offer evidence-based smoking cessation therapies to all smokers, regardless of SOC, may provide an opportunity to reduce the prevalence of smoking. ${ }^{30}$

The Veterans Victory Over Tobacco Study randomized smokers to usual care or to a proactive, populationbased tobacco cessation intervention that offered telephone or in-person counseling, as well as access to cessation medications, to smokers regardless of SOC. The primary results revealed a statistically significant higher population-level 6-month prolonged smoking abstinence rate at 1 year for proactive care $(13.5 \%)$ compared with usual care $(10.9 \%, p=0.02) .{ }^{31}$ In this secondary analysis, we evaluate the effectiveness of proactive care among smokers at different baseline SOC. Our primary question is whether a proactive outreach intervention will increase prolonged abstinence even among those who say they are not ready to quit. Secondary outcomes include the uptake of cessation therapies and quit attempts by smokers at each SOC.

\section{METHODS}

Study Design and Participants. The Veterans Victory Over Tobacco Study was a pragmatic randomized controlled trial, and was approved by the institutional review boards of all participating sites. Current smokers (aged 18 to 80 years) were identified using the US Department of Veterans Affairs (VA) electronic medical record health factor data set. Participants were recruited from October 2009 to September 2010 from four VA medical centers (New York, NY; Jackson, MS; Tampa, FL: Minneapolis, MN), and follow-up was completed in November 2011. Additional details of the trial design and methods were described previously. ${ }^{31,32}$

Treatment. The proactive care intervention comprised proactive outreach (mailed materials followed by telephone outreach) combined with an offer of telephone smoking cessation counseling or referral to in-person counseling. Telephone care included a combination of proactive calls from trained counselors at the Minneapolis VA and facilitated access to smoking cessation pharmacotherapy through the participant's VA provider. The usual care group did not receive proactive outreach but did have access to smoking cessation services through their local VA and their state telephone quitline.

Data Collection. VA administrative and health care utilization data were obtained from the VA National Patient Care Database. Survey data were collected at baseline and 1-year follow-up.

Measures. Nicotine dependence was evaluated at baseline and follow-up using time to first morning cigarette and number of cigarettes per day. ${ }^{33}$ SOC was assessed at baseline and follow-up with the ten-point Readiness to Quit Ladder (RQL). ${ }^{34}$ Ladder responses 1 through 10 were categorized into low (1-4), medium (5-6), and high (7-10) levels of readiness that approximate and are referenced hereafter as precontemplation, contemplation, and preparation (adapted from Abrams et al. ${ }^{34}$ ).

The primary outcome was self-reported 6-month prolonged abstinence at 1-year follow-up, and was assessed among all participants, regardless of treatment utilization. Secondary outcomes included uptake of smoking cessation therapies and quit attempts measured at baseline and follow-up. The use of behavioral counseling (telephone or in-person) and/or smoking cessation medications from any source (including bupropion, varenicline, and nicotine replacement therapy [NRT]) was self-reported. Medications were also assessed using administrative prescription data. Quit attempts were assessed with the question, "During the past 12 months, how many times have you quit smoking intentionally for 24 hours or longer?"

Analysis. We used stratified random sampling (by site) to select the study sample and a completely randomized block design to assign participants to the intervention or usual care. Accordingly, our estimations, testing, and modeling procedures are stratified analyses. To compare baseline 
characteristics across the SOC, the weighted stratified Wald $\chi^{2}$ was used for categorical variables and the weighted stratified $F$-test was used for continuous variables. The weights were inverses of the sampling proportions from each site. To account for possible intra-block correlations, logistic regression mixed modeling was used to test the effect of SOC on the primary outcome, 6-month prolonged abstinence. All models included the intervention and blocking factor (site). We tested the interaction between SOC and treatment arm with respect to the primary outcome. Randomization was not stratified by SOC, which allowed for potentially imbalanced covariates (both measured and unmeasured) between the two treatment arms within each SOC to occur by chance, and this may have created a biased interaction term. To control for betweengroup imbalances, we have presented a stratified analysis, comparing the treatment effect within each SOC separately. Imbalanced characteristics at the 0.05 significance level were included in the models as adjusting covariates.

To handle non-response, we hypothesized that this might depend on the unobserved smoking status of the subject; that is, we assumed a not-missing-at-random (NMAR) mechanism. We modeled the joint distribution of abstinence status and response status for the logistic regressions using an expectation-maximization algorithm to find maximum likelihood estimators, as described by Ibrahim and colleagues. ${ }^{35,36}$ This likelihood-based NMAR method creates two data sets, one that assumes all nonresponders are smokers, and another that assumes they are all quitters. Then, through a series of iterative weightings, it produces maximum likelihood estimates. The data analysis for this paper including the macro for likelihoodbased NMAR modeling was generated using SAS/STAT software, version 9.2 (SAS Institute Inc., Cary, NC, USA).

\section{RESULTS}

Of the 5123 eligible, randomized participants, 3006 provided complete baseline survey data, including the RQL, and thus constitute the sample for this secondary analysis $(58.5 \%$ [1473/2519] of those randomized to the proactive care intervention and $58.9 \%$ [1533/2604] of those in usual care). At baseline, 781 smokers were in precontemplation $(26.0 \%)$, 1148 were in contemplation (38.2\%), and 1077 were in preparation (35.8\%) (Table 1$)$.

Within precontemplation and contemplation, observed baseline characteristics were balanced across treatment groups (Tables 3 and 4, available online). However, for the preparation group, male gender and level of agreement with the statement "People important to me want me to quit smoking" were not balanced across treatment groups (Table 5, available online). These imbalanced variables were included in the complete case and the NMAR models as adjusting covariates.

\section{Primary Outcome: 6-Month Prolonged Absti- nence (Table 2)}

Six-month prolonged abstinence at 1 year varied by baseline SOC (5.4\% for precontemplators, $8.6 \%$ for contemplators, and $17.1 \%$ for preparers $[p<0.001])$. The overall interaction between SOC and treatment arm was not statistically significant $(p=0.30)$. Among smokers in preparation, those randomized to the proactive intervention were more likely to quit than those in usual care $(21.1 \%$ vs $13.1 \%$, respectively, $p=0.003)$. Logistic regression mixed modeling analysis, taking into account treatment arm and facility as well as the adjusting covariates described above, found a significant effect of proactive care compared with usual care among preparers (OR, 1.8 [95 \% CI, 1.2-2.6]). Similarly, smokers in contemplation who were randomized to the proactive intervention were more likely to quit than those in usual care $(11.0 \%$ vs $6.5 \%, \mathrm{p}=0.018$; OR, 1.8, [95 \% CI, 1.1-2.8]).). Smokers in precontemplation quit at similar rates in the two treatment arms $(5.3 \%$ vs $5.6 \%, \mathrm{p}=0.85$; OR, 0.9, [95 \% CI, 0.5-1.9]). Analyses accounting for nonresponse using likelihood-based NMAR models showed a similar effect of the proactive care intervention on prolonged abstinence at each SOC (Table 2). Of the 254 study participants who achieved 6month prolonged abstinence, $55.6 \%$ began the study in preparation, while $44.4 \%$ were not ready to quit at baseline ( $12.5 \%$ began in precontemplation and $31.9 \%$ in contemplation).

\section{Secondary Outcomes}

\section{Uptake of Smoking Cessation Therapies (Fig. 1).}

Smokers at all SOC who were randomized to proactive care engaged in telephone counseling at significantly higher rates than usual-care smokers (7.4 vs. $0.6 \%$ for precontemplation; 16.6 vs $2.7 \%$ for contemplation; 18.8 vs. $3.1 \%$ for preparation) and reported combined therapy with counseling and cessation medication at significantly higher rates than usual care smokers (6.0 vs. $1.5 \%$ for precontemplation; 14.1 vs. $5.7 \%$ for contemplation; 20.7 vs $8.4 \%$ for preparation). Smokers in all SOC who received proactive care were more likely than usual care participants to be prescribed cessation medications through the VA, though this difference reached statistical significance only for contemplation and preparation (20.2 vs. $16.1 \%$ for precontemplation [NS]; 40.9 vs. $33.3 \%$ for contemplation; 44.9 vs. $37.4 \%$ for preparation). Study participants reported using in-person counseling or attending VA smoking cessation clinics at low rates that were not significantly different by study arm or by baseline SOC. 
Table 1 Participant Characteristics by Baseline Stage of Change

\begin{tabular}{|c|c|c|c|c|c|}
\hline & Total, $n$ & $\begin{array}{l}\text { Precontemplation, } \\
n(\%)^{*} \text { or mean (SD) }\end{array}$ & $\begin{array}{l}\text { Contemplation, } \\
n(\%) \text { or mean (SD) }\end{array}$ & $\begin{array}{l}\text { Preparation, } \\
n(\%) \text { or mean (SD) }\end{array}$ & p value \\
\hline All participants & 3006 & 781 & 1148 & 1077 & - \\
\hline \multicolumn{6}{|l|}{ Treatment group } \\
\hline Usual care & $1533(51.3)$ & $396(50.6)$ & $585(50.7)$ & $552(52.5)$ & \multirow[t]{2}{*}{0.64} \\
\hline Proactive care & $1473(48.7)$ & $385(49.5)$ & $563(49.2)$ & $525(47.5)$ & \\
\hline \multicolumn{6}{|l|}{ Demographic characteristics: } \\
\hline Age (years) & $57.7(10.6)$ & $59.4(10.3)$ & $57.0(10.7)$ & $57.3(10.5)$ & $<0.001$ \\
\hline \multicolumn{6}{|l|}{ Race } \\
\hline White & $1852(67.2)$ & $543(74.4)$ & $737(70.0)$ & $572(58.4)$ & \multirow[t]{4}{*}{$<0.001$} \\
\hline Black & $774(22.2)$ & $154(16.4)$ & $280(20.2)$ & $340(29.0)$ & \\
\hline Hispanic & $85(4.5)$ & $41(4.2)$ & $59(3.6)$ & $85(5.8)$ & \\
\hline Other & $95(6.1)$ & $43(5.1)$ & $72(6.2)$ & $80(6.8)$ & \\
\hline \multicolumn{6}{|l|}{ Gender } \\
\hline Male & $2838(94.4)$ & $741(94.9)$ & $1080(94.2)$ & $1017(94.1)$ & 0.71 \\
\hline \multicolumn{6}{|l|}{ Marital status } \\
\hline Married & $1460(50.0)$ & $337(44.8)$ & $602(53.6)$ & $521(50.0)$ & 0.001 \\
\hline \multicolumn{6}{|l|}{ Socioeconomic status: } \\
\hline \multicolumn{6}{|l|}{ Income $(\$)$} \\
\hline$<10,000$ & $511(17.0)$ & $123(16.1)$ & $185(16.0)$ & $203(18.9)$ & \multirow[t]{4}{*}{0.001} \\
\hline $10,000-20,000$ & $879(30.8)$ & $238(32.8)$ & $307(28.1)$ & $334(32.4)$ & \\
\hline $20,001-40,000$ & $841(30.5)$ & $841(29.7)$ & $207(30.4)$ & $323(31.3)$ & \\
\hline$\geq 40,001$ & $593(21.6)$ & $155(21.4)$ & $266(25.5)$ & $172(17.4)$ & \\
\hline \multicolumn{6}{|l|}{ Social and environmental pressures: } \\
\hline \multicolumn{6}{|l|}{ Home smoking rules } \\
\hline Not allowed anywhere & $1116(41.1)$ & $237(33.3)$ & $406(39.8)$ & $473(48.6)$ & \multirow[t]{3}{*}{$<0.001$} \\
\hline Allowed some places/times & $602(20.7)$ & $142(19.2)$ & $219(20.0)$ & $241(22.3)$ & \\
\hline Allowed anywhere & $1087(38.2)$ & $354(47.5)$ & $438(40.2)$ & $295(28.7)$ & \\
\hline \multicolumn{6}{|l|}{ Friends who smoke } \\
\hline None & $454(16.2)$ & $116(15.8)$ & $171(16.2)$ & $167(16.5)$ & \multirow[t]{5}{*}{0.001} \\
\hline$<$ half & $809(28.7)$ & $185(24.6)$ & $296(27.9)$ & $328(32.7)$ & \\
\hline About half & $614(22.2)$ & $163(22.3)$ & $238(22.7)$ & $213(21.7)$ & \\
\hline$>$ half & $530(19.4)$ & $134(18.8)$ & $217(21.0)$ & $179(18.0)$ & \\
\hline All & $384(13.6)$ & $130(18.6)$ & $135(12.2)$ & $119(11.2)$ & \\
\hline \multicolumn{6}{|c|}{ People important to me want me to quit smoking } \\
\hline Strongly disagree to neutral & $580(21.6)$ & $267(37.8)$ & $188(17.9)$ & $125(13.2)$ & \multirow[t]{3}{*}{$<0.001$} \\
\hline Somewhat agree & $628(22.8)$ & $196(26.7)$ & $234(23.1)$ & $198(19.3)$ & \\
\hline Strongly agree & $1569(55.6)$ & $263(35.5)$ & $635(59.0)$ & $671(67.5)$ & \\
\hline \multicolumn{6}{|l|}{ Smoking behaviors: } \\
\hline \multicolumn{6}{|l|}{ Cigarettes per day } \\
\hline$\leq 10$ & $1018(31.3)$ & $211(24.7)$ & $290(22.3)$ & $517(46.7)$ & \multirow[t]{3}{*}{$<0.001$} \\
\hline$\overline{11}-20$ & $1286(45.0)$ & $341(46.3)$ & $547(49.5)$ & $398(38.9)$ & \\
\hline$\geq 21$ & $652(23.7)$ & $213(29.0)$ & $301(28.3)$ & $138(14.4)$ & \\
\hline Time to first cigarette, $\min$ & & & & & \\
\hline$\geq 31$ & $809(25.8)$ & $185(23.2)$ & $249(20.7)$ & $375(33.6)$ & $<0.001$ \\
\hline $6-30$ & $1535(52.6)$ & $402(52.2)$ & $615(55.1)$ & $518(50.1)$ & \\
\hline$<5$ & $638(21.6)$ & $188(24.6)$ & $278(24.2)$ & $172(16.3)$ & \\
\hline Quit in past 12 months & & & & & \\
\hline Yes & $1673(54.4)$ & $181(22.4)$ & $626(53.2)$ & $866(80.6)$ & $<0.001$ \\
\hline Longest quit length & & & & & \\
\hline Never quit & $255(8.3)$ & $128(16.3)$ & $72(6.1)$ & $55(4.7)$ & $<0.001$ \\
\hline$<1$ month & $824(27.1)$ & $230(29.5)$ & $334(27.9)$ & $260(24.2)$ & \\
\hline $1-6$ months & $809(27.2)$ & $187(24.4)$ & $309(27.5)$ & $313(28.9)$ & \\
\hline$>6$ months & $1092(37.5)$ & $225(29.8)$ & $426(38.5)$ & $441(42.2)$ & \\
\hline
\end{tabular}

* Observed count (weighted column proportion)

Quit Attempts. Baseline SOC predicted the likelihood of making a quit attempt during the study period. Overall, $31.3 \%$ of precontemplators, $55.6 \%$ of contemplators, and $73.5 \%$ of preparers reported making at least one 24-hour quit attempt during the study follow-up period. There was no significant difference in quit attempts between proactive and usual care.

\section{DISCUSSION}

This proactive population-based smoking cessation intervention included smokers at all stages of change (SOC), and increased long-term prolonged abstinence for smokers in both preparation and contemplation. Smokers in precontemplation did not quit at higher rates in response to proactive outreach, but they were more likely to try evidence-based cessation interventions, including telephone counseling and combined counseling and pharmacotherapy. Proactively offering evidence-based cessation therapies to all smokers led to increased therapeutic engagement and higher long-term populationlevel quit rates.

Our assessment of an overall interaction between SOC and treatment group revealed no statistically significant difference among SOC subgroups with respect to the 
Table 2 Primary Outcome: 6-Month Prolonged Abstinence by Baseline Stage of Change and Treatment Arm

\begin{tabular}{|c|c|c|c|c|}
\hline \multirow{2}{*}{$\begin{array}{l}\text { Baseline stage of } \\
\text { change }\end{array}$} & \multicolumn{2}{|c|}{ Participants, n (\%)* } & \multirow{2}{*}{$\begin{array}{l}\text { Odds } \\
\text { ratio }^{\dagger} \\
(95 \% \text { CI) } \\
\text { Complete } \\
\text { case } \\
\text { model } \\
n=2351\end{array}$} & \multirow{2}{*}{$\begin{array}{l}\text { Odds } \\
\text { ratio } \\
(95 \% \\
\text { CI) } \\
\text { NMAR } \\
\text { model }^{\S} \\
n=3006\end{array}$} \\
\hline & $\begin{array}{l}\text { Usual } \\
\text { care, } \\
n=1236\end{array}$ & $\begin{array}{l}\text { Proactive } \\
\text { care, } \\
n=1115\end{array}$ & & \\
\hline Precontemplation & $\begin{array}{l}18 \\
(5.6 \%)\end{array}$ & $15(5.3 \%)$ & $\begin{array}{l}0.9(0.5, \\
1.9)\end{array}$ & $\begin{array}{l}1.2(0.8, \\
1.8)\end{array}$ \\
\hline Contemplation & $\begin{array}{l}31 \\
(6.5 \%)\end{array}$ & $\begin{array}{l}48 \\
(11.0 \%)\end{array}$ & $\begin{array}{l}\mathbf{1 . 8}(1.1, \\
2.8)\end{array}$ & $\begin{array}{l}\mathbf{1 . 8} \\
2.4)\end{array}$ \\
\hline Preparation & $\begin{array}{l}60 \\
(13.1 \%)\end{array}$ & $\begin{array}{ll}82 & \\
(21.1 \%)\end{array}$ & $\begin{array}{l}1.8(1.2, \\
2.6)\end{array}$ & $\begin{array}{l}\text { 1.6 (1.4, } \\
2.0)\end{array}$ \\
\hline
\end{tabular}

* Observed count (weighted column proportion)

+ Usual care is the reference group

t Among follow-up survey respondents

$\S$ Likelihood-based NMAR (not-missing-at-random) model accounting for non-response

intervention. Interaction tests are often underpowered and may be biased when the study is not designed to detect these subgroup effects and randomization is not stratified by subgroup. Thus, we presented additional stratified analyses demonstrating the effect of proactive outreach on smokers at each baseline stage. Among highly motivated smokers (preparation), $73.5 \%$ of whom made at least one quit attempt during follow-up,

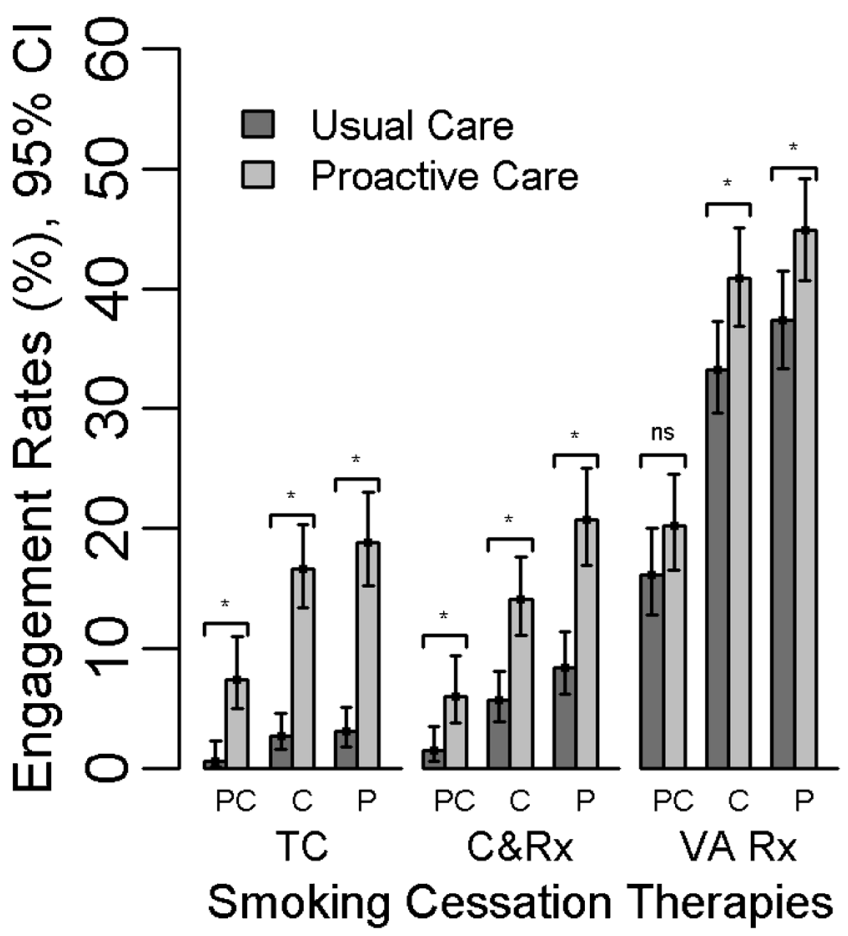

Figure 1 Engagement with smoking cessation therapies by baseline stage of change and treatment $\mathrm{arm} . \mathrm{PC}=$ precontemplation,

$\mathbf{C}=$ contemplation, $\mathbf{P}=$ preparation, $\mathbf{n s}=$ not significant,

TC $=$ telephone counseling, $\mathbf{C} \& \mathbf{R x}=$ counseling $\&$ medication, VA

$R \mathbf{R}=$ VA-prescribed medication. * $95 \%$ confidence interval for odds ratio does not contain 1 . proactive outreach increased the likelihood of quitting successfully by $50 \%(21.1 \%$ vs $13.1 \%)$. Though proactive outreach targets less motivated smokers, ${ }^{37}$ we found that even highly motivated smokers benefited from proactive outreach through increased uptake of cessation therapies.

Proactive outreach to contemplators appeared to increase cessation by helping smokers overcome high nicotine dependence through the use of evidence-based therapies. Contemplators had attempted to quit in the past at rates similar to preparers, but had much higher levels of nicotine dependence (Table 1). A history of past quit attempts is a predictor of future attempts, but nicotine dependence levels predict the success of those attempts. ${ }^{38,39}$ Increased therapeutic engagement by contemplators resulted in more successful quit attempts. Our finding that treatment engagement was associated with cessation (OR 1.55 [95 \% CI 1.06-2.28] for use of combined therapy) supports this proposed mechanism.

Although proactive outreach increased treatment engagement among precontemplators, we did not observe a difference in smoking cessation rates. It may be that proactive outreach that offers standard cessation therapies is ineffective for precontemplators, who face greater barriers to quitting ${ }^{40}$ and may require tailored or highintensity therapy. ${ }^{23}$ Alternatively, our analysis may have been underpowered to show a difference in cessation among precontemplators, given the smaller size of the subgroup and lower baseline quit rates. Further research is needed for a definitive answer to this question. We found no evidence that the proactive intervention increased unsuccessful quit attempts among precon templators $(31.4 \%$ of precontemplators in usual care and $31.3 \%$ in proactive care made at least one quit attempt during follow-up $[p=0.98]$ ), and thus have no reason to believe that proactive care poses harm to precontemplators.

Our results replicate and extend prior research that has evaluated population-based smoking cessation interventions for smokers at all SOC. Since 1995, when Curry and colleagues first demonstrated the potential effectiveness of telephone-based interventions with non-volunteer smokers at all SOC, ${ }^{25}$ dozens of telephone-based trials in various populations have supported this proactive approach. However, most have measured only pointprevalent abstinence and/or found short-term (6-9-month follow-up) effects. ${ }^{37,41,42}$ In contrast, our proactive care intervention achieved prolonged abstinence at long-term (12-month) follow-up among both preparers and contemplators. One reason for this robust effect may be that we combined population-based outreach (using electronic health technology to identify current smokers and to offer telephone-based care) with individual care management 
(linking care to VA providers to facilitate pharmacotherapy). Smokers in proactive care were much more likely to use combined counseling and pharmacotherapy (Fig. 1), which has been shown to be highly effective. ${ }^{4,6}$

While earlier telephone counseling studies have included smokers at all SOC, those studies did not provide information as to whether smokers at lower SOC benefitted from the interventions or merely diluted the population-level treatment effect. In 2015, Haas and colleagues ${ }^{43}$ addressed this deficiency, reporting that their telephone-based intervention using interactive voice response increased abstinence both among those planning to quit within the next 30 days and among those with no plans to quit. Our report provides additional information on the magnitude of the treatment effect on less motivated smokers and divides less motivated smokers into subgroups of precontemplators and contemplators.

Interest in treating smokers at all $\mathrm{SOC}$ has grown over the past decade. In 2005, Pisinger and colleagues first reported the success of the Inter99 trial, which found that a high-intensity intervention could engage less motivated smokers and increase rates of abstinence. ${ }^{23,44}$ Several editorials, citing the success of Inter99, have questioned current guideline recommendations to assess motivation to quit prior to offering cessation therapy. ${ }^{26,45}$ Aveyard and colleagues conducted a systematic review and meta-analysis of brief physician interventions among smokers at all motivation levels and concluded that combining physician advice to quit with the offer of cessation support motivated an additional $40-60 \%$ of smokers to attempt to quit, compared with advice alone. $^{30}$ The authors suggested that offering assistance in quitting to smokers at all SOC may be effective because the offer itself increases confidence in success. To explain why less motivated smokers often respond to offers of cessation therapy, others have advanced an alternative theory of smoking cessation based in "catastrophe theory," which posits that motivational tension fluctuates, and small triggers can induce apparently spontaneous quit attempts. ${ }^{46,47}$

Carpenter and colleagues subsequently reported that among unmotivated smokers, NRT sampling was more successful for inducing quit attempts and short-term cessation than practice quit attempts alone. ${ }^{48}$ Two additional small studies compared the offer of NRT to usual care and found promising short-term results regardless of motivation. ${ }^{49,50}$ After more than a decade of small studies, meta-analyses, and editorials, we now report on the largest low-intensity, pragmatic, proactive care intervention with long-term outcomes among smokers who were not planning to quit at baseline.

Limitations include a study population of mostly older male US veteran smokers, which may limit generalizability to other populations of smokers. Our study, a non-pre-specified sub- group analysis, is restricted to those participants who completed the baseline survey questions that established SOC, and thus this sample may be more engaged than the overall population. Follow-up data availability is limited to an even smaller group. We address the potential for response bias in follow-up data by including a likelihood-based NMAR model analysis. In the primary analysis, ${ }^{31}$ we also addressed possible differential non-response between treatment groups, and found that taking into account non-response bias did not substantially alter the results. Additional limitations result from inconsistencies in operationalizing the TTM across the literature, making it difficult to compare our SOC with those in other studies. ${ }^{9}$

This large, pragmatic randomized trial of a telephone-based intervention demonstrated increased uptake of smoking cessation therapies and prolonged abstinence at 1 year both for smokers who were already planning to quit and for those who were not. Similar to the results of prior studies, ${ }^{23,25}$ we found that among participants who quit successfully, nearly half began the study stating that they were not ready to quit. Restricting therapy to only those in the preparation stage would exclude $64 \%$ of the smokers in our sample, and $44 \%$ of those who quit. Our results add to the growing body of evidence that smoking cessation therapy should be proactively offered to all smokers, regardless of stated plans to quit.

\section{ACKNOWLEDGMENTS:}

\section{Additional Contributors: None.}

Funders: This study was funded by the US Department of Veterans Affairs, Veterans Health Administration, Office of $R e^{-}$ search and Development, and Health Services Research and Development (IAB-05-303), and was registered on ClinicalTrials.gov (NCTO0608426). This work was supported in part by Career Development Award (Japuntich) no. 1IK2CX000918-01A1 from the Clinical Sciences Research and Development Service of the US Department of Veterans Affairs Office of Research and Development. The views expressed in this article are those of the authors and do not necessarily reflect the position or policy of the US Department of Veterans Affairs or the US government.

Prior Presentations: Preliminary results were presented at the Society for Research on Nicotine and Tobacco's SRNT Europe 16th Annual Congress, 2015 Sep 10-12, Maastricht, Netherlands.

Corresponding Author: Steven S. Fu, MD, MSCE; VA HSR\&D Center for Chronic Disease Outcomes ResearchMinneapolis VA Health Care System, Minneapolis, MN, USA (e-mail: Steven.Fu@va.gov).

\section{Compliance with Ethical Standards:}

Conflict of Interest: All study authors declare that they have no conflict of interest.

Open Access This article is distributed under the terms of the Creative Commons Attribution 4.0 International License (http:// creativecommons.org/licenses/by/4.0/), which permits unrestricted use, distribution, and reproduction in any medium, provided you give appropriate credit to the original author(s) and the source, provide a link to the Creative Commons license, and indicate if changes were made. 


\section{Appendix A}

Table 3 Baseline Participant Characteristics by Treatment Group Within Precontemplation

\begin{tabular}{|c|c|c|c|c|}
\hline & Total, $n$ & $\begin{array}{l}\text { Proactive care, } \\
n(\%)^{*} \text { or mean (SD) }\end{array}$ & $\begin{array}{l}\text { Usual care, } \\
n(\%) \text { or mean (SD) }\end{array}$ & p value \\
\hline All participants & 781 & 385 & 396 & - \\
\hline \multicolumn{5}{|l|}{ Demographic characteristics: } \\
\hline Age (years) & $59.4(10.3)$ & $58.8(10.6)$ & $59.9(10.0)$ & 0.06 \\
\hline \multicolumn{5}{|l|}{ Race } \\
\hline White & $543(74.4)$ & $256(71.7)$ & $287(77.0)$ & \multirow[t]{4}{*}{0.25} \\
\hline Black & $154(16.4)$ & $84(17.6)$ & $70(15.2)$ & \\
\hline Hispanic & $41(4.2)$ & $20(4.3)$ & $21(4.0)$ & \\
\hline Other & $43(5.1)$ & $25(6.2)$ & $18(3.8)$ & \\
\hline \multicolumn{5}{|l|}{ Gender } \\
\hline Male & $741(94.9)$ & $366(95.2)$ & $375(94.6)$ & 0.71 \\
\hline \multicolumn{4}{|l|}{ Marital status } & \\
\hline Married & $337(44.8)$ & $181(48.3)$ & $156(41.3)$ & 0.06 \\
\hline \multicolumn{5}{|l|}{ Socioeconomic status: } \\
\hline \multicolumn{5}{|l|}{ Income, $(\$)$} \\
\hline$<10,000$ & $123(16.1)$ & $64(17.3)$ & $59(15.01)$ & \multirow[t]{4}{*}{0.43} \\
\hline $10,000-20,000$ & $238(32.8)$ & $103(29.8)$ & $135(35.6)$ & \\
\hline $20,001-40,000$ & $841(29.7)$ & $107(31.3)$ & $100(28.2)$ & \\
\hline$\geq 40,001$ & $155(21.4)$ & $76(21.7)$ & $79(21.2)$ & \\
\hline \multicolumn{5}{|l|}{ Social and environmental pressures: } \\
\hline Home smoking rules & & & & \\
\hline Not allowed anywhere & $237(33.3)$ & $121(35.1)$ & $116(31.5)$ & \multirow[t]{3}{*}{0.20} \\
\hline Allowed some places/times & $142(19.2)$ & $73(20.8)$ & $69(17.7)$ & \\
\hline Allowed anywhere & $354(47.5)$ & $161(44.1)$ & $193(50.8)$ & \\
\hline \multicolumn{5}{|l|}{ Friends who smoke } \\
\hline None & $116(15.8)$ & $51(14.4)$ & $65(17.0)$ & \multirow[t]{5}{*}{0.75} \\
\hline$<$ half & $185(24.6)$ & $91(24.6)$ & $94(24.6)$ & \\
\hline About half & $163(22.3)$ & 79 (21.4) & $84(23.1)$ & \\
\hline$>$ half & $134(18.8)$ & $70(20.4)$ & $64(17.2)$ & \\
\hline All & $130(18.6)$ & $64(19.2)$ & $66(18.1)$ & \\
\hline \multicolumn{5}{|c|}{ People important to me want me to quit smoking } \\
\hline Strongly disagree to neutral & $267(37.8)$ & $123(36.4)$ & $144(39.1)$ & \multirow[t]{3}{*}{0.19} \\
\hline Somewhat agree & $196(26.7)$ & 109 (29.9) & $87(23.7)$ & \\
\hline Strongly agree & $263(35.5)$ & $118(33.7)$ & $145(37.2)$ & \\
\hline \multicolumn{5}{|l|}{ Smoking behaviors: } \\
\hline Cigarettes per day & & & & \multirow{4}{*}{0.35} \\
\hline$\leq 10$ & $211(24.7)$ & $111(26.4)$ & $100(23.1)$ & \\
\hline$\overline{11}-20$ & $341(46.3)$ & $157(43.7)$ & $184(48.9)$ & \\
\hline$\geq 21$ & $213(29.0)$ & $107(30.0)$ & $106(28.0)$ & \\
\hline \multicolumn{5}{|l|}{ Time to first cigarette (min) } \\
\hline$\geq 31$ & $185(23.2)$ & $94(23.4)$ & $91(23.0)$ & \multirow[t]{3}{*}{0.95} \\
\hline$\overline{6}-30$ & $402(52.2)$ & $196(51.6)$ & $206(52.7)$ & \\
\hline$<5$ & $188(24.6)$ & $92(25.0)$ & $96(24.3)$ & \\
\hline \multicolumn{5}{|l|}{ Quit in past 12 months } \\
\hline Yes & $181(22.4)$ & $91(22.8)$ & $90(22.1)$ & 0.80 \\
\hline \multicolumn{5}{|l|}{ Longest quit length } \\
\hline Never quit & $128(16.3)$ & $65(16.8)$ & $63(15.8)$ & \multirow[t]{4}{*}{0.25} \\
\hline$<1$ month & $230(29.5)$ & $126(32.6)$ & $104(26.4)$ & \\
\hline $1-6$ months & $187(24.4)$ & $83(22.5)$ & $104(26.3)$ & \\
\hline$>6$ months & $225(29.8)$ & $107(28.1)$ & $118(31.5)$ & \\
\hline
\end{tabular}

* Observed count (weighted column proportion) 
Appendix B

Table 4 Baseline Participant Characteristics by Treatment Group Within Contemplation

\begin{tabular}{|c|c|c|c|c|}
\hline & Total, $n$ & $\begin{array}{l}\text { Proactive care, } \\
n(\%)^{*} \text { or mean (SD) }\end{array}$ & $\begin{array}{l}\text { Usual care, } \\
n(\%) \text { or mean (SD) }\end{array}$ & p value \\
\hline All participants & 1148 & 563 & 585 & - \\
\hline \multicolumn{5}{|l|}{ Demographic characteristics: } \\
\hline Age (years) & $57.0(10.7)$ & $56.6(10.9)$ & $57.2(10.4)$ & 0.32 \\
\hline \multicolumn{5}{|l|}{ Race } \\
\hline White & $737(70.0)$ & $358(69.5)$ & $287(70.5)$ & \multirow[t]{4}{*}{0.18} \\
\hline Black & $280(20.2)$ & $150(22.2)$ & $130(18.3)$ & \\
\hline Hispanic & $59(3.6)$ & $26(3.0)$ & $33(4.1)$ & \\
\hline Other & $72(6.2)$ & $29(5.3)$ & $43(7.1)$ & \\
\hline \multicolumn{5}{|l|}{ Gender } \\
\hline Male & $1080(94.2)$ & $530(94.3)$ & $550(94.1)$ & 0.88 \\
\hline \multicolumn{5}{|l|}{ Marital status } \\
\hline Married & $602(53.6)$ & $292(52.8)$ & $310(54.4)$ & 0.60 \\
\hline \multicolumn{5}{|l|}{ Socioeconomic status: } \\
\hline \multicolumn{5}{|l|}{ Income (\$) } \\
\hline$<10,000$ & $185(16.0)$ & $85(15.1)$ & $100(16.8)$ & \multirow[t]{4}{*}{0.81} \\
\hline $10,000-20,000$ & $307(28.1)$ & $154(28.2)$ & $153(28.0)$ & \\
\hline $20,001-40,000$ & $207(30.4)$ & $164(31.6)$ & $159(29.3)$ & \\
\hline$\geq 40,001$ & $266(25.5)$ & $132(25.2)$ & $134(25.9)$ & \\
\hline \multirow{2}{*}{\multicolumn{5}{|c|}{ Social and environmental pressures: }} \\
\hline & & & & \\
\hline Not allowed anywhere & $406(39.8)$ & $209(41.4)$ & $197(38.3)$ & \multirow{3}{*}{0.45} \\
\hline Allowed some places/times & $219(20.0)$ & $97(18.5)$ & $122(21.4)$ & \\
\hline Allowed anywhere & $438(40.2)$ & $214(40.1)$ & $224(40.3)$ & \\
\hline \multicolumn{5}{|l|}{ Friends who smoke } \\
\hline None & $171(16.2)$ & $88(17.1)$ & $83(15.2)$ & \multirow[t]{5}{*}{0.26} \\
\hline$<$ half & $296(27.9)$ & $132(25.1)$ & $164(30.5)$ & \\
\hline About half & $238(22.7)$ & $117(22.4)$ & $121(23.1)$ & \\
\hline$>$ half & $217(21.0)$ & $109(21.7)$ & $108(20.4)$ & \\
\hline All & $135(12.2)$ & $71(13.7)$ & $64(10.8)$ & \\
\hline \multicolumn{5}{|c|}{ People important to me want me to quit smoking } \\
\hline Strongly disagree to neutral & $188(17.9)$ & $95(18.3)$ & $93(17.5)$ & \multirow[t]{3}{*}{0.30} \\
\hline Somewhat agree & $234(23.1)$ & $102(21.0)$ & $132(25.2)$ & \\
\hline Strongly agree & $635(59.0)$ & $321(60.7)$ & $314(57.4)$ & \\
\hline \multicolumn{5}{|l|}{ Smoking behaviors: } \\
\hline \multicolumn{5}{|l|}{ Cigarettes per day } \\
\hline$\leq 10$ & $290(22.3)$ & $140(22.1)$ & $150(22.4)$ & \multirow[t]{3}{*}{0.94} \\
\hline $11-20$ & 547 (49.5) & $274(50.0)$ & $273(48.9)$ & \\
\hline$\geq 21$ & $301(28.3)$ & $143(27.9)$ & $158(28.6)$ & \\
\hline \multicolumn{5}{|l|}{ Time to first cigarette (min) } \\
\hline$\geq 31$ & $249(20.7)$ & $116(20.0)$ & $133(21.4)$ & \multirow[t]{3}{*}{0.41} \\
\hline$\overline{6}-30$ & $615(55.1)$ & $298(54.1)$ & $317(56.1)$ & \\
\hline$<5$ & $278(24.2)$ & $146(26.0)$ & $132(22.5)$ & \\
\hline \multicolumn{5}{|l|}{ Quit in past 12 months } \\
\hline Yes & $626(53.2)$ & $307(54.4)$ & $319(52.1)$ & 0.46 \\
\hline \multicolumn{5}{|l|}{ Longest quit length } \\
\hline Never quit & $72(6.1)$ & $38(6.6)$ & $34(5.5)$ & \multirow[t]{4}{*}{0.70} \\
\hline$<1$ month & $334(27.9)$ & $172(29.1)$ & $162(26.8)$ & \\
\hline $1-6$ months & $309(27.5)$ & $149(27.1)$ & $160(27.9)$ & \\
\hline$>6$ months & $426(38.5)$ & $201(37.3)$ & $225(39.7)$ & \\
\hline
\end{tabular}

* Observed count (weighted column proportion) 


\section{Appendix C}

Table 5 Baseline Participant Characteristics by Treatment Group Within Preparation

\begin{tabular}{|c|c|c|c|c|}
\hline & Total, $n$ & $\begin{array}{l}\text { Proactive care, } \\
n(\%)^{*} \text { or mean (SD) }\end{array}$ & $\begin{array}{l}\text { Usual care, } \\
n(\%) \text { or mean (SD) }\end{array}$ & p value \\
\hline All participants & 1077 & 525 & 552 & - \\
\hline \multicolumn{5}{|l|}{ Demographic characteristics: } \\
\hline Age (years) & $57.4(10.5)$ & $57.2(10.3)$ & $57.6(10.8)$ & 0.47 \\
\hline \multicolumn{5}{|l|}{ Race } \\
\hline White & $572(58.4)$ & $260(55.0)$ & $312(61.6)$ & \multirow[t]{4}{*}{0.20} \\
\hline Black & $340(29.0)$ & $178(31.2)$ & $162(27.1)$ & \\
\hline Hispanic & $85(5.8)$ & $43(6.2)$ & $42(5.4)$ & \\
\hline Other & $80(6.8)$ & $44(7.7)$ & $36(5.9)$ & \\
\hline \multicolumn{5}{|l|}{ Gender } \\
\hline Male & $1017(94.1)$ & $504(95.7)$ & $513(92.6)$ & 0.045 \\
\hline \multicolumn{4}{|l|}{ Marital status } & \\
\hline Married & $521(50.0)$ & $250(50.0)$ & $271(50.1)$ & 0.98 \\
\hline \multicolumn{5}{|l|}{ Socioeconomic status: } \\
\hline \multicolumn{5}{|l|}{ Income (\$) } \\
\hline$<10,000$ & $203(18.9)$ & $98(19.0)$ & $105(18.9)$ & \multirow[t]{4}{*}{0.91} \\
\hline $10,000-20,000$ & $334(32.4)$ & $170(33.4)$ & $164(31.6)$ & \\
\hline $20,001-40,000$ & $311(31.3)$ & $146(31.2)$ & $165(31.4)$ & \\
\hline$\geq 40,001$ & $172(17.4)$ & $81(16.5)$ & $91(18.1)$ & \\
\hline \multicolumn{5}{|l|}{ Social and environmental pressures: } \\
\hline \multicolumn{5}{|l|}{ Home smoking rules } \\
\hline Not allowed anywhere & $473(48.6)$ & $227(48.3)$ & $246(48.9)$ & \multirow{3}{*}{0.58} \\
\hline Allowed some places/times & $241(22.3)$ & $113(21.7)$ & $128(23.7)$ & \\
\hline Allowed anywhere & $295(28.7)$ & $151(30.1)$ & $144(27.4)$ & \\
\hline \multicolumn{5}{|l|}{ Friends who smoke } \\
\hline None & $167(16.5)$ & $85(16.7)$ & $82(16.3)$ & \multirow[t]{5}{*}{0.96} \\
\hline$<$ half & $328(32.7)$ & $149(31.5)$ & $179(33.7)$ & \\
\hline About half & $213(21.7)$ & $104(22.0)$ & $109(21.5)$ & \\
\hline$>$ half & $179(18.0)$ & $92(18.8)$ & $87(17.3)$ & \\
\hline All & $119(11.2)$ & $59(11.1)$ & $60(11.2)$ & \\
\hline \multicolumn{5}{|c|}{ People important to me want me to quit smoking } \\
\hline Strongly disagree to neutral & $125(13.2)$ & $47(10.1)$ & $78(16.0)$ & \multirow[t]{3}{*}{0.031} \\
\hline Somewhat agree & $198(19.3)$ & $99(19.7)$ & $99(18.9)$ & \\
\hline Strongly agree & $671(67.5)$ & $332(70.3)$ & $339(65.1)$ & \\
\hline \multirow{2}{*}{\multicolumn{5}{|c|}{ Smoking behaviors: }} \\
\hline & & & & \multirow{4}{*}{0.67} \\
\hline$\leq 10$ & $517(46.7)$ & $244(45.3)$ & $273(48.0)$ & \\
\hline $11-20$ & 398 (38.9) & $201(40.4)$ & $197(37.7)$ & \\
\hline$\geq 21$ & $138(14.4)$ & $67(14.4)$ & $71(14.4)$ & \\
\hline \multicolumn{5}{|l|}{ Time to first cigarette, $\min$} \\
\hline$\geq 31$ & $375(33.6)$ & $172(32.5)$ & $203(34.5)$ & \multirow[t]{3}{*}{0.75} \\
\hline$\overline{6}-30$ & $518(50.1)$ & $259(50.5)$ & $259(49.8)$ & \\
\hline$<5$ & $172(16.3)$ & $88(17.0)$ & $84(15.7)$ & \\
\hline \multicolumn{5}{|l|}{ Quit in past 12 months } \\
\hline Yes & $866(80.6)$ & $414(80.0)$ & $452(81.1)$ & 0.66 \\
\hline \multicolumn{5}{|l|}{ Longest quit length } \\
\hline Never quit & $55(4.7)$ & $30(5.5)$ & $25(4.1)$ & \multirow[t]{4}{*}{0.11} \\
\hline$<1$ month & $260(24.2)$ & $140(26.4)$ & $120(22.2)$ & \\
\hline $1-6$ months & $313(28.9)$ & $155(29.8)$ & $158(28.2)$ & \\
\hline$>6$ months & $441(42.2)$ & $194(38.4)$ & $247(45.6)$ & \\
\hline
\end{tabular}

* Observed count (weighted column proportion) 


\section{REFERENCES}

1. Centers for Disease Control and Prevention. Quitting smoking among adults-United States 2001-2010. 2011:1513-1519.

2. Centers for Disease Control and Prevention. Current Cigarette Smoking Among Adults-United States, 2005-2013. 2014:1108-1112.

3. Stead LF, Lancaster T. Combined pharmacotherapy and behavioural interventions for smoking cessation. Cochrane Database Syst Rev. 2012;10, CD008286.

4. Kotz D, Brown J, West R. 'Real-world' effectiveness of smoking cessation treatments: a population study. Addiction. 2014;109(3):491-499.

5. Shiffman S, Brockwell SE, Pillitteri JL, Gitchell JG. Use of smokingcessation treatments in the United States. Am J Prev Med. 2008;34(2):102111.

6. Fiore M, Jaen C, Baker T, Bailey W, Benowitz N, Curry S, et al. Treating Tobacco use and Dependence: 2008 Update. Rockville, MD: U.S. Department of Health and Human Services. Public Health Service; 2008.

7. Prochaska JO, DiClemente CC. Transtheoretical therapy: toward a more integrative model of change. Psychother Theory Res Pract Train. 1982; 19:276-288.

8. Spencer L, Pagell F, Hallion M, Adams T. Applying the transtheoretical model to tobacco cessation and prevention: a review of literature. Am J Health Promot. 2002;17(1):7-71.

9. Cahill K, Lancaster T, Green N. Stage-based interventions for smoking cessation. Cochrane Database Syst Rev. 2010;11, CD004492.

10. Prochaska JO, DiClemente CC. Stages and processes of self-change of smoking: toward an integrative model of change. J Consult Clin Psychol. 1983;51(3):390-395.

11. DiClemente CC, Prochaska JO, Fairhurst SK, Velicer WF, Velasquez MM, Rossi JS. The process of smoking cessation: an analysis of precontemplation, contemplation, and preparation stages of change. J Consult Clin Psychol. 1991;59(2):295-304.

12. Prochaska JO. Flaws in the theory or flaws in the study: a commentary on "the effect of transtheoretical model based interventions on smoking cessation". Soc Sci Med. 2009;68(3):404-406.

13. Velicer WF, Fava JL, Prochaska JO, Abrams DB, Emmons KM, Pierce JP. Distribution of smokers by stage in three representative samples. Prev Med. 1995;24(4):401-411.

14. Etter JF, Perneger TV, Ronchi A. Distributions of smokers by stage: international comparison and association with smoking prevalence. Prev Med. 1997;26(4):580-585.

15. Warner KE, Burns DM. Hardening and the hard-core smoker: concepts, evidence, and implications. Nicotine Tob Res. 2003;5(1):37-48.

16. Wewers ME, Stillman FA, Hartman AM, Shopland DR. Distribution of daily smokers by stage of change: current population survey results. Prev Med. 2003;36(6):710-720.

17. ITC Project. ITC United States National Report. Findings from the Wave 1 to 8 Surveys (2002-2011). Waterloo (ON): University of Waterloo; and Charleston (SC): Medical University of South Carolina: 2014.

18. Lundahl BW, Kunz C, Brownell C, Tollefson D, Burke BL. A metaanalysis of motivational interviewing: twenty-five years of empirical studies. Res Soc Work Pract. 2010;20(2):137-160

19. Sciamanna C, Hoch J, Duke GC, Fogle M, Ford D. Comparison of five measures of motivation to quit smoking among a sample of hospitalized smokers. J Gen Intern Med. 2000;15(1):16-23.

20. Herzog TA, Abrams DB, Emmons KM, Linnan L. Predicting increases in readiness to quit smoking: a prospective analysis using the contemplation ladder. Psychol Health. 2000;15(3):369-381.

21. Etter JF, Sutton S. Assessing 'stage of change' in current and former smokers. Addiction. 2002;97:1171-1182.

22. Herzog TA, Blagg CO. Are most precontemplators contemplating smoking cessation? Assessing the validity of the stages of change. Health Psychol. 2007;26(2):222-231.

23. Pisinger $\mathbf{C}$, Vestbo $\mathbf{J}$, Borch-Johnsen $\mathbf{K}$, Jorgensen $\mathbf{T}$. It is possible to help smokers in early motivational stages to quit. The Inter99 study. Prev Med. 2005;40(3):278-284.

24. Tzelepis F, Paul CL, Walsh RA, Wiggers J, Duncan SL, Knight J. Predictors of abstinence among smokers recruited actively to quitline support. Addiction. 2013;108(1):181-185.

25. Curry S, McBride C, Grothaus L, Louie D, Wagner E. A randomized trial of self-help materials, personalized feedback, and telephone counseling with nonvolunteer smokers. J Consult Clin Psychol. 1995;63(6):10051014.

26. West R. Time for a change: putting the transtheoretical (stages of change) model to rest. Addiction. 2005;100(8):1036-1039.
27. Kraft $\mathbf{P}$, Sutton $\mathbf{S}$, Reynolds $\mathbf{H}$. The transtheoretical model of behavior change: are the stages qualitatively different? Psychol Health. 1999; 14:433-450.

28. Herzog TA. Analyzing the transtheoretical model using the framework of Weinstein, Rothman, and Sutton (1998): the example of smoking cessation. Health Psychol. 2008;27(5):548-556.

29. Hughes JR, Keely JP, Fagerstrom KO, Callas PW. Intentions to quit smoking change over short periods of time. Addict Behav. 2005;30(4):653662.

30. Aveyard P, Begh R, Parsons A, West R. Brief opportunistic smoking cessation interventions: a systematic review and meta-analysis to compare advice to quit and offer of assistance. Addiction. 2012;107:1066-1073.

31. Fu SS, van Ryn M, Sherman SE. Proactive tobacco treatment and population-level cessation: a pragmatic randomized clinical trial. JAMA Intern Med. 2014;174(5):671-677.

32. Fu SS, van Ryn M, Sherman SE, Burgess DJ, Noorbaloochi S, Clothier B, et al. Population-based tobacco treatment: study design of a randomized controlled trial. BMC Public Health. 2012;12:159.

33. Chabrol H, Niezborala M, Chastan E, de Leon J. Comparison of the heavy smoking index and of the fagerstrom test for nicotine dependence in a sample of 749 cigarette smokers. Addict Behav. 2005;30(7):1474-1477.

34. Abrams DB, Niaura R, Brown RA, Emmons KM, Goldstein MG, Monti PM. The Tobacco Dependence Treatment Handbook: A Guide to Best Practices. New York: The Guilford Press; 2003.

35. Ibrahim J, Chen M, Lipsitz S. Missing responses in generalised linear mixed models when the missing data mechanism is nonignorable. Biometrika. 2001;88(2):551-564.

36. Fleiss JL, Levin B, Paik MC. Statistical Methods for Rates and Proportions. 3rd ed. New Jersey: Wiley; 2003.

37. Tzelepis F, Paul CL, Walsh RA, McElduff P, Knight J. Proactive telephone counseling for smoking cessation: meta-analyses by recruitment channel and methodological quality. J Natl Cancer Inst. 2011;103(12):922-941.

38. Vangeli E, Stapleton J, Smit ES, Borland R, West R. Predictors of attempts to stop smoking and their success in adult general population samples: a systematic review. Addiction. 2011;106(12):2110-2121.

39. Hyland A, Borland R, Li G, Yong HH, McNeill A, Fong GT, et al. Individual-level predictors of cessation behaviours among participants in the international tobacco control (ITC) four country survey. Tob Control. 2006; 15(Suppl 3):iii83-iii94.

40. Dijkstra A, De VH. Subtypes of precontemplating smokers defined by different long-term plans to change their smoking behavior. Health Educ Res. 2000;15(4):423-434.

41. Tzelepis F, Paul CL, Wiggers J, Walsh RA, Knight J, Duncan SL, et al. A randomised controlled trial of proactive telephone counselling on coldcalled smokers' cessation rates. Tob Control. 2011;20(1):40-46.

42. Stead LF, Hartmann-Boyce J, Perera R, Lancaster T. Telephone counselling for smoking cessation. Cochrane Database Syst Rev. 2013;8, CD002850.

43. Haas JS, Linder JA, Park ER. Proactive tobacco cessation outreach to smokers of low socioeconomic status: a randomized clinical trial. JAMA Intern Med. 2015;175(2):218-226.

44. Pisinger C, Vestbo J, Borch-Johnsen $\mathbf{K}$, Thomsen $\mathbf{T}$, Jorgensen $\mathbf{T}$. Acceptance of the smoking cessation intervention in a large populationbased study: The Inter99 study. Scand J Public Health. 2005;33(2):138145.

45. Richter KP, Ellerbeck EF. It's time to change the default for tobacco treatment. Addiction. 2015;110(3):381-386.

46. Brown C. Chaos and Catastrophic Theories: Quantitative Applications in the Social Sciences. London: Sage; 1995.

47. West R, Sohal T. "Catastrophic" pathways to smoking cessation: findings from national survey. BMJ. 2006;332(7539):458-460.

48. Carpenter MJ, Hughes JR, Gray KM, Wahlquist AE, Saladin ME, Alberg AJ. Nicotine therapy sampling to induce quit attempts among smokers unmotivated to quit: a randomized clinical trial. Arch Intern Med. 2011;171(21):1901-1907.

49. Cropsey KL, Hendricks PS, Jardin B, Clark CB, Katiyar N, Willig J, et al. A pilot study of screening, brief intervention, and referral for treatment (SBIRT) in non-treatment seeking smokers with HIV. Addict Behav. 2013;38(10):2541-2546.

50. Jardin BF, Cropsey KL, Wahlquist AE, Gray KM, Silvestri GA, Cummings KM, et al. Evaluating the effect of access to free medication to quit smoking: a clinical trial testing the role of motivation. Nicotine Tob Res. 2014;16(7):992-999. 